maintain the audit initiated by the inquiry the UK thalassaemia register now collects information about the circumstances of each new affected birth.

We thank Paula Williamson and Mark Griffin for statistical advice.

Contributors: BM provided data from the UK thalassaemia register, participated in planning data collection and analysis, checked and analysed all data, and drafted the paper. $\mathrm{RH}$ conceived and implemented the concept of the genetic confidential inquiry, obtained financial support, supervised and coordinated all modules, participated in planning data analysis, and edited the paper. BL participated in planning data collection and analysis, conducted the inquiry, collected and entered the data, participated in planning data analysis, coordinated the study, and edited the paper. MK ensured that data from the UK thalassaemia register was complete, helped identify responsible obstetricians, and assisted in checking data. MD contributed to the principles of data analysis and edited the paper. ML provided data from the UK register of prenatal diagnosis for haemoglobin disorders and some patient records, and participated in planning data analysis. MP and JO provided data from the UK register of prenatal diagnosis for haemoglobin disorders, checked patient records, and participated in planning data analysis. LV provided data from the UK register of prenatal diagnosis for haemoglobin disorders and checked patient records. RH and BM will act as guarantors for the paper.

Funding: The UK Confidential Enquiry into Counselling for Genetic Disorders was sponsored by the Royal College of Physicians and supported by the UK Department of Health. BM is supported by the Wellcome Trust as a prinical research fellow.

Competing interests: None declared.

1 Harris R. How well do we manage families with genetic problems? national confidential enquiry into counselling for genetic disorders should tell us. BMJ 1991;303:1412-3.

2 Harris R, Lane B, Harris HJ, Williamson P, Dodge J, Modell B, et al. National confidential enquiry into counselling for genetic disorders by non-geneticists: general recommendations and specific standards for improving care. Brit J Obst Gynaecol 1999;106:658-63.

3 National confidential enquiry into counselling for genetic disorders Homozygous beta thalassaemias, Great Britain 1990-94. Report to the Department of Health from the steering committee, 1998.
4 Sickle cell, thalassaemia and other haemoglobinopathies. Report of a working party of the Standing Medical Advisory Committee. London: HMSO, 1994.

5 Modell B, Petrou M, Layton M, Varnavides L, Slater C, Ward RHT, et al. Audit of prenatal diagnosis for haemoglobin disorders in the United Kingdom: the first 20 years. BMJ 1997;315:779-84.

6 Modell B, Khan M, Darlison M. Survival in beta thalassaemia major in the United Kingdom: data from the UK thalassaemia register. Lancet 2000 (in press).

7 Nuffield Council on Bioethics. Genetic screening, ethical issues. London: Nuffield Council on Bioethics.

8 Working party of the General Haematology Task Force of the British Committee for Standards in Haematology. Guideline. The laboratory diagnosis of haemoglobinopathies. Brit J Haematol 1998;101:783-92.

9 Neuenschwander $\mathrm{H}$, Modell $\mathrm{B}$. The process of antenatal sickle cell screening at a north London hospital. BMJ 1997;315:784-5.

10 Old JM, Varawalla NY, Weatherall DJ. Rapid detection and prenatal diagnosis of beta-thalassaemia: studies in Indian and Cypriot populations in the UK. Lancet 1990;336:834-7.

11 Modell B, Ward RHT, Fairweather DVI. Effect of introducing antenata diagnosis on the reproductive behaviour of families at risk for thalassaemia major. BMJ 1980;2:737-40.

12 Modell B, Petrou M, Ward RHT, Fairweather DVI, Rodeck C, Varnavide LA, et al. Effect of fetal diagnostic testing on the birth-rate of thalassaemia in Britain. Lancet 1985;2:1383-6.

13 Modell B. EC concerted action on developing patient registers as a tool for improving service delivery for haemoglobin disorders. In: Fracchia GN, Theophilatou M, eds. Health services research. Amsterdam: IOS Press, 1993.

14 Health Education Authority. Sickle cell and thalassaemia: achieving health gain. Guidance for commissioners and providers. London: HEA, 1998.

15 Hickman M, Modell B, Greengross P, Chapman C, Layton M, Gill M, et al Mapping the prevalence of sickle cell and $\beta$ thalassaemia in England: recommended rates for local service planning. Brit J Haematol 1999;104: 860-7.

16 Modell M, Wonke B, Anionwu E, Khan M, See Tai S, Lloyd M, et al. A multidisciplinary approach for improving services in primary care: the example of screening for haemoglobin disorders. BMJ 1998;7161: $788-91$.

17 Anionwu EN. Ethnic origin of sickle and thalassaemia counsellors; does it matter? In: Kelleher D, Hillier D, eds. Research in cultural differences in health. Routledge: London, 1996.

18 Petrou M, Modell B. Prenatal screening for haemoglobin disorders. Prenat Diag 1995;15:1275-95.

19 Jones D, Gill P. Breaking down language barriers: the provision of accessible interpreting services for all. BMJ 1998;316:1476.

(Accepted 29 November 1999)

\title{
Quality of life related to fear of falling and hip fracture in older women: a time trade off study
}

\author{
G Salkeld, I D Cameron, R G Cumming, S Easter, J Seymour, S E Kurrle, S Quine
}

\begin{abstract}
Objective To estimate the utility (preference for health) associated with hip fracture and fear of falling among older women.

Design Quality of life survey with the time trade off technique. The technique derives an estimate of preference for health states by finding the point at which respondents show no preference between a longer but lower quality of life and a shorter time in full health.

Setting A randomised trial of external hip protectors for older women at risk of hip fracture.

Participants 194 women aged $\geqslant 75$ years enrolled in the randomised controlled trial or who were eligible for the trial but refused completed a quality of life interview face to face.

Outcome measures Respondents were asked to rate their own health by using the Euroqol instrument and then rate three health states (fear of falling, a "good" hip fracture, and a "bad" hip fracture) by using time trade off technique.
\end{abstract}

Results On an interval scale between 0 (death) and 1 (full health), a "bad" hip fracture (which results in admission to a nursing home) was valued at 0.05 ; a "good" hip fracture (maintaining independent living in the community) 0.31 , and fear of falling 0.67 . Of women surveyed, $80 \%$ would rather be dead (utility $=0$ ) than experience the loss of independence and quality of life that results from a bad hip fracture and subsequent admission to a nursing home. The differences in mean utility weights between the trial groups and the refusers were not significant. A test-retest study on 36 women found that the results were reliable with correlation coefficients within classes ranging from 0.61 to 0.88 .

Conclusions Among older women who have exceeded average life expectancy, quality of life is profoundly threatened by falls and hip fractures. Older women place a very high marginal value on their health. Any loss of ability to live independently in the community has a considerable detrimental effect on their quality of life.
Social and Public Health Economics Research Group (SPHERe),

Department of Public Health and Community Medicine, University of Sydney, New South Wales 2006,

Australia

G Salkeld

senior lecturer

continued over

BMJ 2000;320:241-6 
Department of

Public Health and

Community

Medicine,

University of

Sydney

R G Cumming

associate professor

J Seymour

research scholar

S Quine

associate professor

Rehabilitation

Studies Unit,

Department of

Medicine,

University of

Sydney, PO Box 6

Ryde, New South

Wales 1680,

Australia

I D Cameron

associate professor

Hornsby

Ku-ring-gai

Hospital, New

South Wales 2077

Australia

S Easter

research assistant

S E Kurrle

director of

rehabilitation and

aged care service

Correspondence to: G Salkeld glenns@

pub.health.

usyd.edu.au

\section{Introduction}

Hip fractures are a major cause of morbidity and mortality, and almost all occur after a fall. ${ }^{1}$ In the next 50 years the number of hip fractures will probably increase greatly. ${ }^{1-3}$ About $20 \%$ of people who fracture their hips are dead within a year, ${ }^{4-6}$ and many of those who recover from hip fracture require additional assistance in daily living. ${ }^{4}$ Population data tend to obscure the personal impact of falls and hip fracture. Objective measures of function, such as activities of daily living ${ }^{8}$ and subjective utility based measures of health related quality of life, ${ }^{9}$ can express the personal dimension. Hip fracture adversely affects health related quality of life, with greater physical recovery reflected in better quality of life. ${ }^{10}$ Thus, health related quality of life is an important outcome for studies attempting to reduce the number of falls or their consequences. ${ }^{11}$ As part of an ongoing randomised trial (the community hip protector trial) that is examining the effectiveness of hip protectors in older women living in the community we sought to estimate the utility (preference for health) associated with falls that cause a fear of falling or hip fracture in older women.

\section{Methods}

Study participants-The community hip protector study is a randomised controlled trial involving women aged 75 years and older who are at high risk of hip fracture and who live in their own homes. Older women living in the northern suburbs of Sydney, Australia, who had contact with an aged care health service and met inclusion criteria were invited to participate in the study. These criteria were age greater than 74 years; two or more falls, or one fall resulting in hospital treatment, in the past year; at least one hip without previous surgery; likely to continue to live in the community for at least three months; likely to survive for at least one year; English speaker; and able to give informed consent. ${ }^{12}$ A sample of women from the hip protector trial as well as a group of women who had refused to participate in the trial were approached to participate in the quality of life study. The sample included all women randomised into the trial (or who refused to enter the trial) from April 1997 to July 1998. Thus the study elicited values from women who had direct experience in wearing the hip protectors (the intervention group), women who did not have experience in wearing the hip protectors but were aware of the trial (the control group), and women who had refused to participate in the trial because they would not wear the hip protectors if randomised to the intervention group (refusers). The study was approved by the ethics committees of participating hospitals. The quality of life interview schedule was administered to the women six months after they were recruited into the trial (or after refusal to enter).

Health states-To develop descriptions of health states we reviewed the literature and interviewed older women. Sixteen open ended quality of life interviews were conducted with women who had had no contact at all with trial and who had experienced a hip fracture. The interviews helped to define the dimensions of quality of life most affected by a hip fracture and the language used by women to describe their experiences.
Data from the qualitative research and clinical opinion were used to generate four "name labelled" health states. The health states were full health (Anne), fear of falling (Mary), a good hip fracture (Jean-where the respondent returns from hospital to independent living in the community), and a bad hip fracture (Elizabeth-where the respondent moves to a nursing home). (See the appendix for descriptions of the health states.)

Interview schedule-Respondents were introduced to the purpose of the quality of life study and the format of the interview. Each respondent was asked to rate her own health for each of the five dimensions of Euroqol (EQ-5D) and to assess whether her current health was better, worse, or the same as it was 12 months ago. EQ-5D scores were calculated by using the utility weights of values from a general population survey in the United Kingdom. ${ }^{13}{ }^{14}$ In the next stage of the interview, respondents were introduced to the four health states. They were asked to rank the four health states from best to worst. Respondents were then asked to trade off shorter periods of life in full health for longer periods of life with lower quality of life. We used the converging "ping pong" technique to identify their point of indifference. ${ }^{15}$ We used actual life expectancy as the time horizon for our study. Women aged 75-84 years (most of our study subjects) were given a 10 year time horizon; women aged 85 years and older were given a five year time horizon. To mitigate any ordering effects, the presentation of scenarios was randomly allocated before the interview.

Scoring the time trade off response-The time trade off technique asks the respondent to choose between two alternatives, both of whose outcomes are known with certainty. ${ }^{14}$ In this study participants were asked to consider living in a state of less than full health $\left(h_{<f u l}\right)$ for a defined period of time ( $t=5$ or 10 years, depending on their age) and then die. The alternative was to live for a shorter period of time in full health ( $h_{\text {full }}$, represented by the health state "Anne") and then die. The time $(x)$ in full health was varied until the subject was indifferent between the two alternatives. The choice scenarios were presented to subjects in six month and one year increments for the five and 10 year interview schedules, respectively. If a respondent would trade off no more than six months or one year (respectively) then they were asked to trade off in smaller increments of one or two months, respectively. The utility weight for each state is given by the formula $x / t .^{9}$

Sample size-Power calculation data for comparisons of mean utility scores for independent respondent groups were made by using the guide by Furlong et al. ${ }^{15}$ We estimated that 70 women in each group would be needed to detect a difference in mean utility scores of 0.1 on the interval scale where $\alpha=0.05$, power $=80 \%$, and $\mathrm{SD}=0.2$ around the mean score. $\mathrm{A}$ $10 \%$ difference in mean utility score was chosen because it was considered that this represented an important difference in quality of life.

Baseline health assessment-The general health status and functional capacity of participants was assessed at baseline before randomisation into the trial. The short form- $12^{16}$ and activities of daily living (Barthel) index ${ }^{8}$ were administered to each participant in a face to face interview and scored with published scoring algorithms. 
Table 1 Characteristics and health status of respondents (at interview) by group. Figures are numbers (percentage) of women unless stated otherwise

\begin{tabular}{|c|c|c|c|c|}
\hline Characteristic & Control $(n=76)$ & Intervention $(\mathrm{n}=\mathbf{8 4})$ & Refusers ( $n=43$ ) & Total $(\mathrm{n}=203)$ \\
\hline Mean (range) age (years) & $83(75-97)$ & $83(75-98)$ & $83(75-92)$ & $83(75-98)$ \\
\hline Age $75-84$ years & $44(58)$ & $54(64)$ & $28(65)$ & $126(62)$ \\
\hline Aged $\geqslant 85$ years & $32(42)$ & $30(36)$ & $15(35)$ & $77(38)$ \\
\hline Mean No of falls in past 12 months & 2.5 & 2.7 & NA & 2.6 \\
\hline Previous hip fracture & $18(24)$ & $22(26)$ & NA & $40(25)$ \\
\hline Mean (median) No of days in hospital in past 12 months & $17(13)$ & $14(8.5)$ & NA & $15(10)$ \\
\hline \multicolumn{5}{|l|}{ General health (compared with 12 months ago): } \\
\hline Better (\%) & 16 & 10 & 5 & 11 \\
\hline Same (\%) & 32 & 41 & 44 & 38 \\
\hline Worse $(\%)$ & 52 & 50 & 51 & 51 \\
\hline EQ-5D & 0.76 & 0.77 & 0.77 & 0.77 \\
\hline Mean (SD) SF-12 physical score & $36.3(10.7)$ & $39.3(10.2)$ & NA & $37.8(10.5)$ \\
\hline Mean (SD) SF-12 mental score & $52.7(7.8)$ & $52.7(8.3)$ & NA & $52.7(8.0)$ \\
\hline Mean score for activities of daily living: & 97.3 & 97.5 & NA & 97.4 \\
\hline Median (25th, 75th centile) & $100(95,100)$ & $100(100,100)$ & & $100(95,100)$ \\
\hline \multicolumn{5}{|l|}{ Country of birth: } \\
\hline Australia & $55(72)$ & $72(86)$ & NA & $127(79)$ \\
\hline Overseas & $21(28)$ & $12(14)$ & & $33(21)$ \\
\hline \multicolumn{5}{|l|}{ Income: } \\
\hline Pension (welfare) & $53(70)$ & $61(73)$ & NA & $114(71)$ \\
\hline Superannuation or private means & $23(30)$ & $23(27)$ & & $46(29)$ \\
\hline \multicolumn{5}{|l|}{ Education: } \\
\hline Primary school & $4(5)$ & $5(6)$ & NA & $9(5)$ \\
\hline Some secondary school & $17(22)$ & $16(19)$ & & $33(21)$ \\
\hline Completed secondary school & $22(29)$ & $24(29)$ & & $46(29)$ \\
\hline Trade apprenticeship & $15(20)$ & $20(24)$ & & $35(22)$ \\
\hline Certificate/diploma & $12(16)$ & $13(16)$ & & $25(16)$ \\
\hline University degree & $6(8)$ & $6(7)$ & & $12(7)$ \\
\hline
\end{tabular}

NA=not applicable.

Test-retest reliability study-We readministered the interview schedule to 36 respondents three weeks after their initial interview to assess the reliability of using time trade off in an older population group. The reliability of the utility weights was assessed with the intraclass correlation coefficient. ${ }^{17}$

Distribution of the time trade off scores-The mean utility weights for both hip fracture states were highly skewed towards zero. Therefore the Mann-Whitney test for comparing two independent samples has been used when appropriate.

\section{Results}

From 1 September 1997 to 31 December 1998 we completed 203 quality of life interviews. There were 84 respondents in the intervention group, 76 in the control group, and 43 in the refusers group. The response rate by group (the number of interviews divided by the number of people asked for an interview) was $86 \%, 88 \%$, and $31 \%$, respectively. Each interview took, on average, 63 minutes to complete. Table 1 presents a summary of respondent characteristics and health status. There were no significant differences between the groups in self rated health, in the short form-12, activities of daily living, or EQ-5D ( $t$ test and $\chi^{2}$ test statistic, respectively). For all three groups about half the participants reported that their health was worse when compared with their health 12 months previously.

\section{Consistency of ranked health states with the time} trade off weight

We checked the consistency of the utility weights by comparing the ranking for each of the four primary health states with the value elicited by the time trade off technique. Nine respondents (four control, four intervention, and one refuser) whose utilities were not ranked in the expected order were excluded from further analysis of the data.

Descriptive analysis-time trade off utility weights

Health states-Table 2 shows the mean, median, and interquartile range of time trade off scores for 194 subjects by state and age group. Respondents in all groups placed a high marginal value on health. The low mean (and median) utility weight for a "bad" hip fracture $(0.05$ and 0.0 , respectively) indicates that most women were prepared to trade off considerable length of life to avoid the reduction in quality of life that happens after a hip fracture. There was greater variability in the utility weights for a "good" hip fracture, with an interquartile range of scores from 0.0-0.65. The distinguishing feature between a good and a bad hip fracture was

Table 2 Mean (median) time trade off utility weights for health states by age group

\begin{tabular}{|c|c|c|c|}
\hline \multirow[b]{2}{*}{ Group } & \multicolumn{3}{|c|}{ Health state } \\
\hline & $\begin{array}{l}\text { Fear of falling } \\
\text { (Mary) }\end{array}$ & $\begin{array}{l}\text { Good hip fracture } \\
\text { (Jean) }\end{array}$ & $\begin{array}{l}\text { Bad hip fracture } \\
\text { (Elizabeth) }\end{array}$ \\
\hline \multicolumn{4}{|l|}{ Age $75-84$ years $(n=120)$} \\
\hline Mean & 0.70 & 0.34 & 0.06 \\
\hline Median (25th, 75th centile) & $0.85(0.65,0.99)$ & $0.15(0.0,0.75)$ & 0 \\
\hline \multicolumn{4}{|l|}{ Age $\geqslant 85$ years $(n=74)$} \\
\hline Mean & 0.62 & 0.26 & 0.05 \\
\hline Median (25th, 75th centile) & $0.75(0.15,0.99)$ & $0.05(0.0,0.55)$ & 0 \\
\hline \multicolumn{4}{|l|}{ Total $(\mathrm{n}=194)$} \\
\hline Mean & 0.67 & 0.31 & 0.05 \\
\hline Median (25th, 75th centile) & $0.85(0.35,0.99)$ & $0.13(0.0,0.65)$ & 0 \\
\hline
\end{tabular}


admission to a nursing home. Nearly all women would trade off almost their entire life expectancy to avoid the state of being admitted to a nursing home. Eighty per cent of respondents said that they would rather be dead. The results were also analysed by respondent group. Participants in the refuser group, who had refused to take part in the hip protector trial, provided lower mean utility weights for each health state compared with participants in either the control or intervention group. There were, however, no significant differences in utility weights between the respondent groups. We compared the valuations of those women in our study who had previously fractured a hip (25\% of the total sample) with women who had not fractured a hip and there was no difference in values between these two groups.

Reliability-The intraclass correlation coefficient (and 95\% confidence intervals) for each health state were 0.88 (0.84 to 0.92 ) for fear of falling (Mary), 0.61 (0.48 to 0.75 ) for good hip fracture (Jean), and 0.73 (0.69 to 0.76 ) for bad hip fracture (Elizabeth). Other time trade off studies have reported test-retest reliability coefficients ranging from 0.63 (at six weeks) to 0.87 at one week or less. ${ }^{18-20}$ The values derived in this study can be considered reliable.

\section{Discussion}

The results of this study are very clear: older women place a very high marginal value on their health. The low mean utility weights for "Jean" and "Elizabeth" show that a hip fracture represents a profound threat to their health related quality of life. The single most important factor (threat) seems to be the loss of independence, dignity, and possessions that accompanies the move from living in their own homes to living in a nursing home. It is difficult to estimate accurately the proportion of women experiencing the "bad" hip fracture health state. Data from the Northern Sydney hip fracture audit, however, show that of women living at home before their hip fracture, $22 \%$ moved to nursing home care in the 12 months after fracture and only $24 \%$ were walking as well as before the fracture. ${ }^{21}$

The utility weights for hip fracture provide interesting contrasts with other health states. A casual observation would suggest that a hip fracture is worse than breast cancer (time trade off utility weight 0.75 ), ${ }^{22}$ myocardial infarction $(0.90),{ }^{23}$ or mild osteoarthritis $(0.69) .{ }^{24}$ Direct comparisons are difficult because utility weights vary across age groups and application of the time trade off technique varies between studies, but our findings emphasise the gravity of hip fractures in the minds of older women who are at risk of sustaining this injury.

It is interesting to consider why women rate the utility of falls and especially hip fractures so low. These views have presumably been influenced by the experience of their parents, friends, and siblings. The views are largely congruent with the poor objective outcomes of hip fracture, although rather more dramatic in our view. ${ }^{21}$

The results also highlight a valuation effect related to age. Respondents often commented that they were living on borrowed time (all had lived beyond a "normal" span of "three score years and ten") and that they had lived a good or fair life (a "fair innings"). ${ }^{2.5}$

\section{What is already known on this topic}

There is almost no evidence on the acceptability, usefulness, and reliability of the time trade off technique as a method for assessing health values of older people living independently in the community

The health values of hospitalised patients aged 80 years or older has been assessed with the time trade off technique (the HELP project) but until now evidence on quality of life fear of falling and hip fracture has been lacking

\section{What this paper adds}

Hip fractures among older women can have a profound effect on quality of life

Eighty per cent of women surveyed would rather be dead than experience the loss of independence and quality of life that results from a bad hip fracture and subsequent admission to a nursing home

Any loss to living independently in the community has a significant detrimental effect on their quality of life, and it follows that a reduction in the incidence of hip fractures will not only save lives but will prevent a considerable reduction in their quality of life

Although the quality of life interview did not specifically ask respondents about equity issues (such as who gets health care and how much), their verbal comments during the exercise revealed that they believed in the "fair innings" argument. Respondents did reflect on their health throughout their lifetime. They did not want to live on borrowed time at the expense of younger people. At their age, death was expected and preferable to a state of health that meant losing their home, their independence, and their normal quality of life. We had some concern about applying utility measurement techniques in a population aged in their $80 \mathrm{~s}$ and $90 \mathrm{~s}$. There was almost no evidence on the acceptability, usefulness, and reliability of the time trade off technique versus other techniques for this age group. ${ }^{20}{ }^{26} \mathrm{We}$ found that the very nature of the time trade off exercise encouraged the respondents to talk about the trade off between length of life and quality of life, a matter that most women had at least considered before the interview. Nearly three quarters of the participants found the time trade off questions easy or fairly easy, and just $8 \%$ of subjects found the questions very difficult. The intraclass correlation coefficients from the test-retest reliability study show that the time trade off technique is a reliable measurement tool in this age group.

The findings of this study should be applicable to all frail older women who have sustained injury after a fall or who have fallen without injury. The utility weights derived in this study should inform clinical management of falls, for both doctor and patient. These results support the implementation of interventions that have been shown to be effective in reducing falls and injury from falls in frail older women..$^{27-29}$

Among older women who have exceeded average life expectancy, quality of life matters. Older women 
place a very high marginal value on their health. Any loss to living independently in the community has a significant detrimental effect on their quality of life. It follows that a reduction in the incidence of hip fractures will not only save lives but will prevent a significant reduction in their quality of life.

Contributors: GS was responsible for the original idea (quality of life study), study design, data analysis, and writing the paper; IDC was responsible for the original idea (randomised trial), study design, recruitment of subjects, and writing the paper; RGC participated in the study design, data analysis, and generation of health state descriptions; SE participated in data collection, qualitative research methods, and writing the paper; JS participated in the study design and data analysis; SEK participated in recruitment of subjects and generation of health state descriptions; SQ participated in qualitative research methods and generation of health state descriptions. GS is the guarantor.

Funding: National Health and Medical Research Council of Australia Public Health Research and Development Grant.

Competing interests: None declared.

\section{Appendix}

\section{Full health-Anne}

Anne is a similar age to you. She lives in her own home and cares for herself. Anne is active in her local community and is out and about with friends quite a bit. She swims regularly and enjoys visiting her children each weekend. Anne walks without any aids and can manage her 12 steps at home without any problems. She enjoys shopping and cooking for herself. Anne does not need any help with the housework and derives pleasure and relaxation from gardening.

\section{Fear of falling-Mary}

Mary is a similar age to you. She lives alone in her own home and cares for herself. Mary is involved in community fundraising and enjoys playing bridge. Mary recently had a fall. She did not break any bones but was badly cut and bruised. She is scared of falling. Mary continues to walk without aids. She still looks after herself and does her own housework. Mary has been a bit depressed since her fall. She has returned to her bridge group but is anxious when she is outside the home because she is scared of falling again.

\section{Good hip fracture-Jean}

Jean is a similar age to you. She lives in her own home and cares for herself. Before her fall Jean was out and about quite a bit with her church group. She swam on a regular basis and occasionally looked after her grandchildren. Jean broke her hip when she fell. She is finding it difficult to do everything at home now that she walks with a stick. She needs help in shopping as she no longer drives or feels confident to shop alone. She can prepare only simple meals and is missing being able to bake for her friends. Jean can no longer manage the housework by herself. She misses her church activities but finds it too painful and tiring to be out for long periods. Jean experiences feelings of frustration and anger. Jean gets tearful thinking about all the things she can't do.

\section{Bad hip fracture-Elizabeth}

Elizabeth is a similar age to you. Until her recent fall, she lived in her own home and managed to care for herself. She was active in her local community.
Elizabeth broke her hip when she fell. She is now unable to live alone as she requires a great deal of help to do most things. Elizabeth now lives in a nursing home near to her family but away from her friends. She is limited in where she can walk because of the frame and is unable to walk for long distances. She is unable to shower or dress without help from the nurse. She is unable to pursue her gardening or community work. Her leg aches sometimes at night. She has become anxious and is easily upset.

1 Kannus P, Niemi S, Palvanen M, Parkkari J. Fall-induced injuries among elderly people. Lancet 1997;350:1174.

2 Kannus P. Preventing osteoporosis, falls, and fractures among elderly people. $B M J 1999 \cdot 318 \cdot 205-6$.

3 Melton LJ. Epidemiology of hip fractures: implications. Bone 1996;18:121-5S

4 Cumming RG, Nevitt MC, Cummings SR. Epidemiology of hip fractures Epidemiol Rev 1997;19:244-57.

5 Jacobsen SJ, Goldberg J, Miles TP, Brody JA, Stiers W, Rimm AA. Race and sex differences in mortality following fracture of the hip. Am J Public Health 1992;82:1147-50.

6 Cooper C, Atkinson EJ, Jacobsen SJ, O'Fallon WM, Melton LJ 3rd. Population-based study of survival after osteoporotic fractures. Am J Epidemiol 1993;137:1001-5.

7 Mossey JM, Mutran E, Knott K, Craik R. Determinants of recovery 12 months after hip fractures: the importance of psychosocial factors. Am J Public Health 1989;79:279-86.

8 Mahoney FI, Barthel DW. Functional evaluation: the Barthel index. $M d$ State Med J 1965; 14:61-5.

9 Torrance GW. Measurement of health state utilities for economic appraisal: a review. J Health Econ 1986;5:1-30.

10 Kane RL, Qing C, Finch M, Blewett L, Burns R, Moskowitz M. Functiona outcomes of posthospital care for stroke and hip fracture patients under medicare. J Am Geriat Soc 1998;46:1525-33.

11 Torgerson DJ, Kanis JA. Cost-effectiveness of preventing hip fractures in the elderly population using vitamin D and calcium. $Q M J 1995 ; 88: 135-9$.

12 Cameron ID, Stafford B, Cumming R, Birks C, Lockwood K, Quine S. Hip protectors improve falls self-efficacy. Age Ageing (in press).

13 Dolan P, Gudex C, Kind P, Williams A. The time trade-off method-results from a general population study. Health Econ 1996a;5:141-54.

14 Dolan P, Gudex C, Kind P, Williams A. Valuing health states: a comparison of methods. J Health Econ 1996b;15:209-31.

15 Furlong M, Feeney D, Torrance GW, Barr R, Horsman J. Guide to design and development of health-state utility instrumentation. Ontario: Centre for Health Economics and Policy Analysis, McMaster University, 1990. (Working paper series No 90-9.)

16 Gandek B, Ware JE, Aaronson NK, Apolone G, Bjorner JN, Brazier JE. Cross validation of item selection and scoring for the SF-12 health survey in nine countries: results from the IQOLA project. International quality of life assessment. J Clin Epi 1998;51:1171-8.

17 Armitage PA, Berry G. Statistical methods in medical research. Oxford: Blackwell, 1984.

18 Forberg DG, Kane RL. Methodology for measuring health-state preferences. 11. Scaling methods. J Clinical Epidemiol 1989;42:459-71.

19 Nease RF, Kneeland GT, O'Connor W, Sumner C, Lumpkins L, Shaw, L, et al. Variations in patient utilities for outcomes of the management of chronic stable angina: implications for clinical practice guidelines. Ischaemic health disease patient outcomes research team. JAMA $1995 ; 273: 1185-90$

20 Brazier J, Deverill M, Green C, Harper R, Booth A. A review of the use of health state measurements in economic evaluation. Health Tech Assess 1999;3:1-164.

21 March L, Chamberlain A, Cameron I, Cumming RG, Kurrle SF Finnegan T, et al. Prevention, treatment and rehabilitation of fractured neck of femur. Report of the Northern Sydney area fractured neck of femur health outcomes project. Sydney: Northern Sydney Area Health Service, 1996

22 Richardson J, Hall J, Salkeld G. The measurement of utility in multiphase health states. Int J Technol Assess Health Care 1996;12:151-62.

23 Glasziou P, Bromwich S, Simes RJ. Quality of life six months after myocardial infarction treated with thrombolytic therapy. Med J Aus 1994; 161:532-6

24 Laupacis A, Bourne R, Rorback, C, Feeny D, Wong C, Tugwell P, et al. The effect of elective total hip replacement on health-related quality of life. $J$ Bone Joint Surg 1993;75A:1619-26.

25 Williams A. Intergenerational equity: an exploration of the "fair innings" argument. Health Economics 1997;6:117-32.

26 Tsevat J, Dawson NV, Wu AW, Lynn J, Soukup J, Cook EF, et al. Health values of hospitalised patients 80 years or older. JAMA 1998;279:371-5.

27 Tinetti ME, Baker DI, McAvay G, Claus EB, Garrett P, Gottschalk M, et al A multifactorial intervention to reduce the risk of falling among elderly people living in the community. N Engl J Med 1994;331:821-7.

28 Campbell AJ, Robertson MC, Gardiner MM, Norton RN, Tilyard MW, Buchner DM. Randomised controlled trial of a general practice programme of home based exercise to prevent falls in elderly women. BMJ 1997:315:1065-9.

29 Close J, Ellis M, Hooper R, Glucksman E, Jackson S, Swift C. Prevention of falls in the elderly trial (PROFET): a randomised controlled trial. Lance 1999;353:93-7.

(Accepted 24 September 1999) 


\title{
Commentary: Older people's perspectives on life after hip fractures
}

\author{
Shanthi N Ameratunga, Paul M Brown
}

Injury Prevention Research Centre, Department of Community Health, Faculty of Medicine and Health Sciences, University of Auckland, Private Bag 92019,

Auckland,

New Zealand

Shanthi N

Ameratung senior research fellow

Department of Community Health, Faculty of Medicine and Health

Sciences

Paul M Brown senior lecturer in health economics

Correspondence to: S Ameratunga s.ameratunga@ auckland.ac.nz
The 20th century witnessed the addition of 30 years to our life expectancy and the ageing of the "baby boom" generation. With the global population of people aged over 75 projected to increase by almost 140\% from 1990 to $2020,{ }^{1}$ the article by Salkeld et al is a timely and provocative exploration of the threat to the quality of life of older people posed by falls and hip fracture. The results suggest older Australian women place a high marginal value on their health and independence, with $80 \%$ preferring death to a "bad" hip fracture that would result in admission to a nursing home.

Health values, preferences, or utilities are incorporated directly or indirectly in the development of interventions and allocation of resources for the prevention and treatment of hip fractures. A salient question is whose values? The values expressed by older people may differ substantially from those of surrogate decision makers (for example, caregivers, health providers, or funding authorities). ${ }^{2}$ Salkeld et al use a subjective preference based measure to explore the perspective of older people regarding the quality of life after falls and hip fracture. The findings are neither interchangeable with nor a substitute for previous research conclusions primarily based on mortality statistics, clinical indices, and "objective" psychometric health status measures. Prospective controlled population based studies that use such objective measures have shown dramatic declines in physical function and mobility and concurrent increases in functional dependence and institutionalisation directly attributable to hip fractures. ${ }^{34}$ While the correlation between psychometric and preference based measures is typically modest, ${ }^{5}$ the research findings of Salkeld et al are broadly complementary and support the conclusion that hip fractures are a serious threat to the quality of life of older people.

The finding that as many as $80 \%$ of older women preferred death to a "bad" hip fracture is disturbing. Such a preference for death, however, is not unique and has been observed in relation to chronic states such as coma, recurrent pain, severe dysfunction, and, indeed, institutionalisation and social isolation. ${ }^{6}$ Although the respondents in this study may have been "sensitised" to the adverse outcomes of fractures because of their association with a hip protector trial, the assigned values did not significantly differ between those who did or did not participate in the trial or those who had or had not experienced a previous hip fracture.

How then are we to interpret this finding? The limited qualitative analysis suggests the preferences expressed were substantially influenced by respondents' concerns regarding the loss of independence after a hip fracture. The results do not, however, imply that $80 \%$ of older women who experience a "bad" fracture would prefer death to treatment. The preferences of individuals who have not experienced such a fracture may change over time because of the moderating influences of adaptation, coping, and adjustment. Others have observed significant differences in values assigned to current compared with future health, temporary compared with chronic illness, and hypothetical compared with personal experiences. $^{6-8}$ The findings are also likely to be specific for time, culture, and context. ${ }^{59}$ The "bad" hip fracture descriptor may be less potent in a community where the health and quality of life of older people is not equated with their ability to live and function independently.

Notwithstanding the above, the study has important implications for individual patient care and preventive interventions relating to falls and hip fracture. It affirms the need for rehabilitation programmes to focus not only on enhancing patients' mobility and functional activities but also to optimise their ability to live independently and participate in social and other aspects of community life. More particularly, the findings indicate the need for older people to be active participants in the decision making around priorities for the prevention and management of falls and hip fracture. The "cognitive burden" implied in empirical studies of health preferences does not vitiate the importance of these processes.

1 Murray CJL, Lopez AD, eds. The global burden of disease. Vol 1. Geneva: World Health Organisation, 1996

2 Tsevat J, Dawson NV, Wu AW, Lynn J, Soukup JR, Cook EF, et al. Health values of hospitalised patients 80 years and older. JAMA 1998;279: $371-6$

3 Norton R, Butler M, Robinson E, Lee-Joe T, Campbell AJ. Declines in physical functioning attributable to hip fracture among older people: a follow-up study of case-control participants. Disability Rehabil a follow-up
(in press).

4 Cumming RG, Klineberg R, Katelaris A. Cohort study of risk of institutionalisation after hip fracture. Am J Public Health 1996;86: $557-60$

5 Revicki DA, Kaplan RM. Relationship between psychometric and utilitybased approaches to the measurement of health-related quality of life Oual Life Res 1993:2:477-87.

6 Patrick DL, Erickson P. Health status and health policy: quality of life in health care evaluation and resource allocation. New York, Oxford University Press, 1993.

7 Ashby J, O'Hanlon M, Buxton MJ. The time trade-off technique: how do the valuations of breast cancer patients compare to those of other groups? Qual Life Res 1994:3:257-65.

8 Froberg DG, Kane RL. Methodology for measuring health-state preferences: II. Scaling methods. J Clin Epidemiology 1989;42:459-71.

9 Loomes G, McKenzie L. The use of QALYs in health care decision making. Soc Sci Med 1989;28:299-308.

\section{Endpiece}

\section{On ageing: contentment}

If I live to be old, for I find I go down, Let this be my fate in a country town; May I have a warm house with a stone at the gate And a cleanly young girl to rub my bald pate. May I govern my passion with an absolute sway, And grow wiser and better as my strength wears away, Without gout or stone, by a gentle decay.

Theater of Musick, Walter Pope, 1630-1714 Submitted by Fred Charatan, retired geriatric psychiatrist, Florida 